\title{
THEY DRIVE AT NIGHT - CAN VISUAL ENHANCEMENT SYSTEMS KEEP THE DRIVER IN CONTROL?
}

\author{
Erik Hollnagel $^{1,2}$ \\ Johan Karlsson, Thomas Magnusson \& Ulrika Taube ${ }^{2}$ \\ (1) Cognitive Systems Engineering Laboratory \\ (2) Department of Computer and Information Science \\ University of Linköping, SE-581 83 Linköping, Sweden \\ E-mail: erik.hollnagel@ida.liu.se
}

\begin{abstract}
Summary: Driving requires a combination of open-loop and closed-loop control. The open-loop control is affected by the quality of visual input, and therefore constrained during driving at night. This study investigated the effects of a Visual Enhancement System during simulated night driving conditions. It was hypothesised that the VES would improve the driver's control, hence the quality of driving. 40 Ss drove about $120 \mathrm{~km}$ on a simulated Swedish road with and without a VES. At the time of writing, the experiments have just finished. Data analysis will focus on derived measures that correspond to the driver's degree of control.
\end{abstract}

\section{INTRODUCTION}

The ability efficiently and safely to drive a car is very much a case of feedforward control or an open-loop process. Drivers do not just react or respond to what they see, but also try to anticipate events in the traffic environment - in particular the movement of other objects. To evaluate apparatus designed to enhance the quality of driving, it is therefore necessary to consider driving as a dynamic process, and focus on the extent to which drivers are able to maintain effective control of the vehicle and realise their intentions on the road.

\section{Driving As A Joint System}

The basis for describing how a driver-vehicle ensemble performs can be found in the notion of a joint cognitive system (Hollnagel \& Woods, 1983). The fundamental principles of this view are shown in Figure 1. The effective performance of the joint system requires that a balance is struck between feedforward and feedback control as the driver's actions are determined in the main by two things. One is the feedback from responses, which is used to control and regulate driving. A major part of this is the closed-loop control that enables experienced drivers to maintain speed, position, separation distance, etc., with a minimum of effort (McRuer et al., 1977). The other is the feedforward from the current understanding to regulating and controlling actions. This enables drivers to respond in anticipation to what they expect will happen at the next moment. Examples are braking (or accelerating), swerving, changing gears, dipping headlights, etc. 


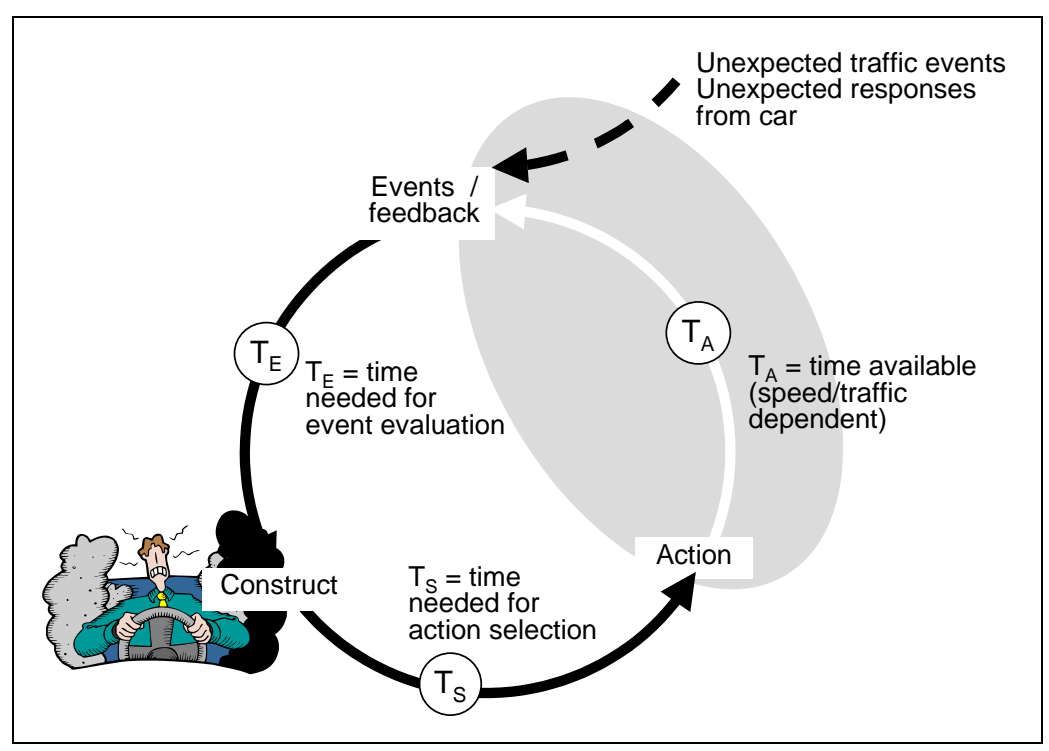

Figure 1: Basic time relations in dynamic control tasks.

\section{Time Dynamics Of Driving}

Since driving is the control of a dynamic process, it is important to consider how time plays a role in driving, and how the various aspects of driving affect time. Following the joint system model, two basic time relations characterised the ability to remain in control. These are the time needed to evaluate events and maintain an adequate situation construct and the time needed to select an appropriate action. If the time needed to evaluate $\left(\mathrm{T}_{\mathrm{E}}\right)$ is larger than the time available $\left(T_{A}\right)$, then control will sooner or later be lost. Similarly, if the time needed to select an action $\left(T_{S}\right)$ is larger than $T_{A}$, then drivers are likely to select an inappropriate action or respond too late - again leading to a loss of control of driving. (In practice, the comparison involves $\mathrm{T}_{\mathrm{E}}+\mathrm{T}_{\mathrm{S}}$ versus $\mathrm{T}_{\mathrm{A} .)}$

In driving, $\mathrm{T}_{\mathrm{A}}$ is determined by several factors such as vehicle speed, driving environment (road, topology, weather), quality of visual and auditory input, traffic density and traffic behaviour, functionality of the vehicle, driver experience, etc. For driving it is in principle possible to increase $\mathrm{T}_{\mathrm{A}}$ by reducing the speed of the vehicle, although drivers may not always be able to this completely at will. As a first approximation one can nevertheless assume that the ability to maintain a steady speed and avoid conflicts, relative to the constraints of the environment, are good several indicators of how much a driver is in control.

\section{The Visual Enhancement System (VES)}

The driver's current understanding is in the main determined by what can be seen. It is characteristic that experienced drivers look quite far ahead, approximately 100-400 meters depending on road conditions and the speed of their own vehicle. Experienced drivers try to anticipate what will happen, such as changes in traffic movements, traffic lights, road characteristics, the possibility of unexpected events, etc., and missed detection in driving is more often due to wrong expectations than to impaired vision (Rumar, 1991). Driving during night therefore presents a problem, because the visual information is both reduced in quantity and degraded in quality. At night, the driver can basically see what is within the range of the headlights, as well as what emits light 
of its own (traffic signals, other vehicles, buildings, etc.). It follows from this that the driver's ability to anticipate what will happen is constrained, and that the style or quality of driving therefore will change. Since the driver's expectations are less detailed, reactions will be more sudden and less adequate. This problem can be overcome by using infrared sensing technology to provide supplementary information that can be shown on a synthesised display. If a driver is provided with additional visual information from a Visual Enhancement System (VES), it will improve the ability to anticipate the road ahead, and to some extent compensate for the night condition. This will in turn enable better feed-forward, hence less variation in speed and steering wheel movements. Driver performance can thus be measured in terms of behavioural entropy (Boer, 2000) or by considering the dynamic dependencies between $T_{E}, T_{S}$ and $T_{A}$.

\section{METHOD}

\section{Simulation Environment}

A fixed-base driving simulator with a $115^{\circ}$ field-of-view was set up at the VR laboratory at Linköping University. The physical environment included an adjustable driver's seat, steering wheel, pedals and speedometer. The software, developed by Virtual Technology in Linköping, provided a full vehicle model in a virtual environment and ran on five networked Dell Dimension 8100-computers. Three SONY VPL-PX-21 LCD video projectors presented the road environment on a custom-built, winged projection wall.

Only dipped headlights were available to the participants and the visual range in the simulation was constrained to a maximum of 100 meters, gradually decreasing beyond 70 meters. The transmission was in automatic mode in order to simplify the driving task as far as possible. No other traffic was present in either direction. A four channel sound system provided realistic ambient sound.

\section{VES Image}

The VES-image was superimposed onto the presentation of the environment using a separate video projector. The simulated VES-image was generated by applying to the virtual environment file a new set of textures, adjusted to give a monochromatic "IR-like" image. The visual range of the VES was 700 meters with a camera angle of 24 degrees. The fields-of-view of the presented VES-image were 12x4 and 18x6 degrees respectively.

\section{Road description}

A rural road environment was modelled according to guidelines from the Swedish Department of Traffic. The road had one lane in each direction, shoulders and a middle marker. All in all there were about $35 \mathrm{~km}$ of road, laid out in a figure eight. The same road was used for all sessions, including practice, although starting points and direction of driving differed between conditions.

\section{Events}

The experiment was conducted in two rounds, preceded by a short familiarisation period. The first round, without the VES, was intended to make the Ss familiar with the driving simulator and to provide a baseline measure. The second round was the actual trial round with VES. The first 
round was approximately $40 \mathrm{~km}$ and included two events; the second round approximately 80 $\mathrm{km}$, and included four events. The characteristics of the events are shown in Table 1.

Table 1: Events used in VES experiment.

\begin{tabular}{l|l|l|l|l|l}
\hline \multicolumn{2}{c|}{ Session 1 - no VES } & \multicolumn{3}{c}{ Session 2 - VES present } \\
\hline Event & Description & Timing & Event & Description & Timing \\
\hline 1 & $\begin{array}{l}\text { Pedestrian standing at one } \\
\text { fourth of the distance from } \\
\text { the roadside to the middle } \\
\text { marker in the right lane }\end{array}$ & $\begin{array}{l}\text { Start + 15 } \\
\text { min }\end{array}$ & 1 & $\begin{array}{l}\text { Pedestrian standing in the middle of the } \\
\text { right lane }\end{array}$ & $\begin{array}{l}\text { Start + 10 } \\
\text { min }\end{array}$ \\
\cline { 2 - 6 } & $\begin{array}{l}\text { A moose, with its front feet } \\
\text { in the middle of the right } \\
\text { lane }\end{array}$ & $\begin{array}{l}\text { Start + 25 } \\
\text { min }\end{array}$ & 3 & $\begin{array}{l}\text { Car parked by the roadside, with a person } \\
\text { standing outside the driver's door }\end{array}$ & $\begin{array}{l}\text { Start + 30 } \\
\text { min }\end{array}$ \\
\hline $\begin{array}{ll}\text { distance from the roadside to the middle } \\
\text { marker }\end{array}$ & $\begin{array}{l}\text { Start + 45 } \\
\text { min }\end{array}$ \\
\cline { 3 - 6 } & 4 & $\begin{array}{l}\text { Moose, with its front feet in the middle of } \\
\text { the right lane }\end{array}$ & $\begin{array}{l}\text { Start + 55 } \\
\text { min }\end{array}$ \\
\hline
\end{tabular}

\section{Subjects}

A total of 43 experienced drivers participated in the study. The subjects had all held a driving license for more than five years and had more than $50.000 \mathrm{~km}$ of driving experience each (cf. Nilsson \& Alm, 1996). The participants had volunteered to participate in the experiment following public announcements on billboards at local stores and on car windshields at parking lots of two major industries. The Ss were randomly assigned to four different conditions with ten Ss in each group. Three female and one male Ss had to discontinue driving due to simulator sickness.

\section{Independent And Dependent Variables}

The main independent variables were driving with or without VES as well as size and brightness-contrast of the VES display. The two sizes were small $\left(12^{\circ}\right.$ horizontal field of view, considered the smallest practical size) and large $\left(18^{\circ}\right.$ horizontal field of view, considered the largest practical size). In the low brightness-contrast condition the VES showed humans, animals and warm parts of vehicles but no parts of the surroundings. In the high brightness-contrast condition, the VES showed what essentially was an inverted grey scale image of the environment displayed in the simulator.

The main dependent variable was the quality of driving performance, corresponding to the concept of orderliness of performance (Hollnagel, 2000). Quality of driving performance is a composite measure derived from a set of more fundamental measures such as reaction time to obstacles perceived on the road or on the VES, changes in vehicle speed (acceleration, deceleration), variation in speed, steering wheel position, accelerator and brake pedal measure and lateral position of the vehicle on the road.

The main hypothesis was that the use of a VES during night driving would enhance the quality of driving. The study further looked into the effects of the display angle, where it was assumed that a wide-angle display would yield significantly better driver performance than a narrow-angle display, and the effects of display intensity, where it was assumed that a high-intensity display yields significantly better driver performance than a low-intensity display. 


\section{Study Design And Procedure}

The study used a 2x2 factorial between-Ss design, with Ss randomly assigned to the different conditions. All Ss were briefed about the study procedure upon their arrival to the driving simulator and informed that they were allowed to discontinue the driving at any time. The driving instructions were to drive to a specified destination as they normally would, following directions on road and traffic signs. After adjusting their seat the Ss drove for a few minutes to get used to the simulator. When Ss reported being ready to start the test, further instructions were given and the first 30 minutes session started. Between the two sessions there was a short (10-15 minutes) break with refreshments. The second session was about 60 minutes long and the conditions were the same as in the first session, except for the presence of the VES. After the second session, Ss went through a short debriefing when the six "events" was replayed in order for them to see how they had driven and provide an opportunity to explain their actions. Finally Ss were asked to complete a short questionnaire about the simulator and driving with a VES.

\section{Data Collection And Analysis}

The data collected - speed, steering wheel position, accelerator and brake pedal positions, lateral position on the road, off road flag and collision flags - were sampled at a $20 \mathrm{~Hz}$ rate. Elapsed time was recorded with all data. A flag was set when an obstacle was visible to the driver (with / without VES). Distance to obstacles was calculated and added to the data files after the experiment. The first 10 minutes of test-driving were excluded from the analysis to avoid effects of driver's learning to use the VES.

A pre-test questionnaire was be used to collect data about Ss' age, gender, driving experience etc. Post-test questionnaires and/or interviews were used to collect data the Ss' impression both of the system per se and how well the simulation worked.

The full data analysis will consider driving smoothness, the reactions to the different events, and the questionnaire data. Possible derived measures include reactions, defined as either sudden reduction in accelerator position and the resulting deceleration or sudden steering wheel movement, and associated reaction times. Driving quality will be measured in terms of smoothness of acceleration and deceleration and lateral position on the road. A baseline performance for comparison will be established from all Ss training runs. The preliminary analysis shows that use of a VES significantly changes driving and increases $\mathrm{T}_{\mathrm{E}} / \mathrm{T}_{\mathrm{A}}$. On the other hand, there were no systematic differences between the various conditions (size and brightness of VES).

\section{REFERENCES}

Boer, E. R. (2000). Behavioural entropy as an index of workload. In Proceedings of the IEA 2000/HFES 2000 Congress

Hollnagel, E. (2000). Modelling the orderliness of human action. In R. Amalberti \& N. Sarter (Eds.), Cognitive engineering in the aviation domain. Hillsdale, NJ: Erlbaum.

Hollnagel, E. \& Woods, D. D. (1983). Cognitive systems engineering: New wine in new bottles. International Journal of Man-Machine Studies, 18, 583-600.

McRuer, D. T., Allen, W., Weir, D. H. and Klein, R. H. (1977). New results in driver steering control. Human Factors, 19(4), 381-397. 
Nilsson, L. \& Alm, H. (1996). Effects of a Vision Enhancement System on Drivers’ Ability to Drive Safely in Fog. VTI-särtryck, no 264.

Rumar, K. (1991). Ögat och mörkertrafiken. Skandia. Stockholm; Team Tryck AB. 